\title{
Posttranscriptional Modulation of Bacteriophage P22 Scaffolding Protein Gene Expression
}

\author{
SHERWOOD CASJENS* AND MARK B. ADAMS \\ Department of Cellular, Viral, and Molecular Biology, University of Utah Medical Center, Salt Lake City, Utah 84132
}

Received 3 July 1984/Accepted 26 September 1984

\begin{abstract}
The bacteriophage P22 late operon contains 2 genes whose products are required for cell lysis and 13 genes whose products are involved in the morphogenesis of the phage particle. This operon is under the positive control of the phage gene 23 product and is thought to have a single promoter. The expression of one of these late genes, the scaffolding protein gene, is autogenously modulated independently from the remainder of the late genes. When unassembled, scafiolding protein turns down the rate of synthesis of additional scafiolding protein, and when it is assembled into phage precursor structures, it does not. Experiments presented here show (i) that the mRNA from the scaffolding protein gene is functionally threefold more stable when most of the scaffolding protein is assembled than when it is unassembled and (ii) that no new promoter near the scaffolding protein gene is activated at the high level of synthesis. These data support the model that this autogenous modulation occurs at a posttranscriptional level. We also observed that another message, that of coat protein, appears to become increasingly stable with time after phage infection.
\end{abstract}

The pathway of bacteriophage P22 head assembly has been studied extensively and is quite well understood (reviewed in references 7 and 15). A unique feature of this assembly process is the catalytic requirement of a protein called scaffolding protein. About 200 to 250 molecules of scaffolding protein coassemble with about 420 molecules of the coat protein and several minor proteins to form proheads, the precursor particles into which DNA is packaged. During the complex DNA packaging reaction, all of the scaffolding protein molecules leave the structure and can reassemble with newly synthesized coat protein and minor proteins to form new proheads.

We have shown elsewhere that expression of the phage P22 scaffolding protein gene (gene 8 ) is autogenously regulated $(5,37)$. Although the scaffolding protein gene occupies an internal position in the late operon of the phage, unassembled scaffolding protein can specifically depress expression of the scaffolding protein gene. When this scaffolding protein is assembled into phage precursor structures, it cannot exercise this regulatory function. Thus, the rate of scaffolding protein synthesis is controlled by its state of assembly $(5,15)$. The $\mathrm{P} 22$ late region is transcribed as a single, large polycistronic message $(34,36)$. It therefore seemed reasonable that the negative autogenous regulation of the scaffolding protein gene might be mediated at some step after mRNA synthesis.

In the experiments here, we have measured the in vivo functional half-lives of the mRNA from each of several P22 late genes and have found that the autogenous regulation of the scaffolding protein can be explained in terms of selective mRNA inactivation.

\section{MATERIALS AND METHODS}

Phage and bacterial strains. The nonsuppressing ( $\left.\sup \mathbf{p}^{0}\right)$ bacterial host used was DB7000 (22). The nonsense alleles carried by the phages used were those described by Botstein et al. (3). All of the strains used in these studies carried the 13- $a m \mathrm{H} 101$ and $c 1-7$ mutations to block lysis and ensure lytic growth, respectively.

\footnotetext{
* Corresponding author.
}

Preparation and analysis of rifampin-treated infected-cell extracts. Strain DB7000 was grown to $2 \times 10^{8}$ cells per $\mathrm{ml}$ in M-9 minimal medium (3) at $30^{\circ} \mathrm{C}$ and infected with the phage at a multiplicity of infection of 7 . After late protein synthesis had begun (at 44 min after infection unless otherwise indicated), rifampin (Calbiochem-Behring) was added to a final concentration of $500 \mu \mathrm{g} / \mathrm{ml}$ (from a methanol solution of 50 $\mathrm{mg}$ of rifampin per $\mathrm{ml}$; control experiments showed that the addition of this amount of methanol alone did not affect phage-directed protein synthesis). Samples $(0.5 \mathrm{ml})$ were withdrawn at 30-s intervals and labeled for $1 \mathrm{~min}$ with $\left[{ }^{35}\right.$ S $]$ methionine (Amersham Corp.) at $40 \mu \mathrm{Ci} / \mathrm{ml}$. Labeling was stopped by diluting a sample directly into 3 volumes of hot $\left(95^{\circ} \mathrm{C}\right)$ sodium dodecyl sulfate (SDS) sample buffer $(20)$ and immediately boiling for $1 \mathrm{~min}$. Proteins were separated by SDS-polyacrylamide slab gel electrophoresis, visualized by autoradiography, and quantitated by microdensitometry as previously described (15).

\section{RESULTS}

Because of the ill-defined relationship between chemical and functional decay of mRNAs $(6,21,38)$ and since any control mechanism that acts at the level of mRNA stability must necessarily affect the functional decay, we chose to study only the latter aspect of the P22 late mRNA decay. Rifampin has often been used to block the initiation of mRNA synthesis in vivo, so that the decay of previously synthesized mRNAs can be followed. The in vivo functional stability for individual mRNAs can be measured by determining the decay of the rate at which specific proteins encoded by the RNAs are made at various times after RNA synthesis is stopped by rifampin addition $(24,28)$.

To determine the functional half-lives of the mRNAs for P22 late proteins, cells were infected with phage P22 and pulse-labeled with $\left[{ }^{35} \mathrm{~S}\right]$ methionine at various times after the addition of rifampin, as described above. Each of the labeled samples was analyzed by SDS-polyacrylamide gel electrophoresis. An autoradiogram of one such experiment is shown in Fig. 1. The intensity of each protein band represents its rate of synthesis at the time of labeling. The intensity of each of the phage-specific bands visible in the 


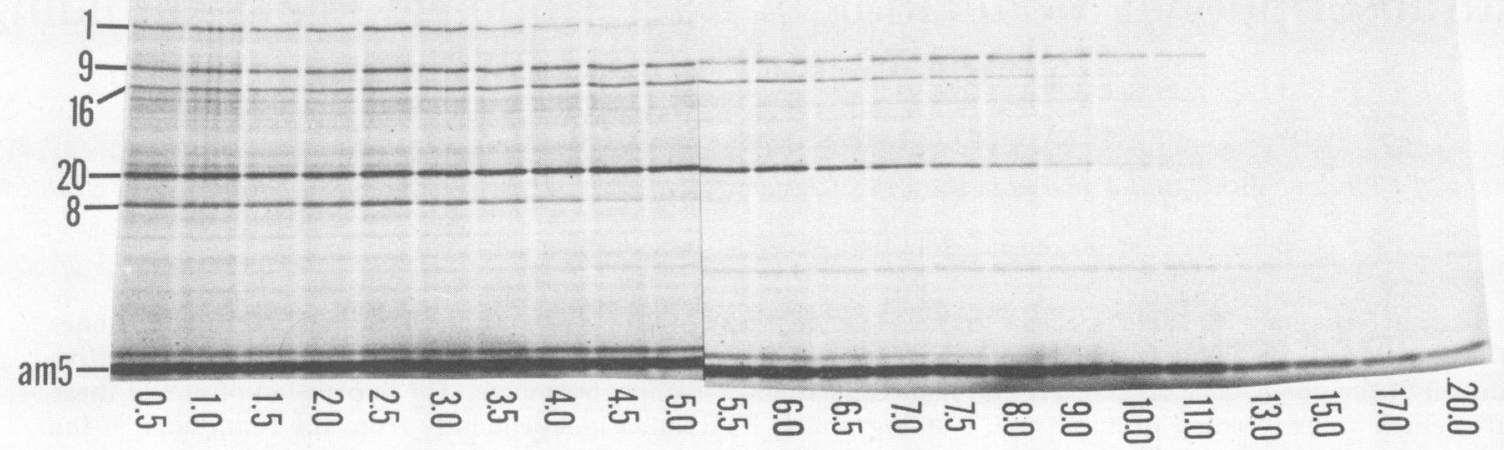

FIG. 1. SDS-polyacrylamide gel electrophoresis of proteins made after rifampin addition. Cells were grown, infected with P22 c1-7 $5^{-} a m \mathrm{~N} 11413^{-}$am H101, labeled with [ ${ }^{35}$ S/methionine after rifampin addition at 44 min after infection, harvested, subjected to SDSpolyacrylamide gel electrophoresis, and autoradiographed as described in the text. The numbers on the left are the genes that encode the indicated proteins (am5 is the amber fragment generated by the $5^{-}$am N114 mutation). Numbers at the bottom are minutes after rifampin addition. Each time represents the midpoint of each 1-min labeling period.

autoradiogram was quantitated by microdensitometry, and the relative amounts of label in each of the individual bands were plotted as functions of time after rifampin addition. Although host protein synthesis can be suppressed by UV light irradiation before P22 infection (3), the experiments were performed in unirradiated cells to avoid potential disruption of RNA metabolism and the low absolute level of phage-directed protein synthesis in irradiated cells $(3,12)$. We were able to quantitate 6 (gp1, gp5, gp8, gp9, gp16, and gp20; gpX refers to the protein product of gene $X$ where $X$ is any gene of $\mathrm{P} 22$ ) of the 15 late gene proteins; the others are masked by host proteins in the gel autoradiographs. The functional decay curves for transcripts corresponding to genes $1,5,8,9,16$, and 20 in P22 wild-type-, $5^{-}$, and $2^{-}$-infected cells $\left(3^{-}\right.$infections show decay curves identical to $2^{-}$infections) are shown in Fig. 2 through 7 , respectively. These genes all encode proteins required for P22 particle assembly, and all lie in the P22 late operon.

All of the curves in Fig. 2 through 7 have the same general shape, with a lag period followed by exponential decay. The duration of the lag presumably represents the time it took RNA polymerase to transcribe the region between the late promoter and the gene in question, since rifampin inhibits the initiation of new RNA chains but not the elongation of previously initiated chains (24). If the rate of transcription is uniform, then the lag time should accurately reflect the physical distance from the late promoter to the gene in question. The individual lag times plotted against the distances of the genes from the late promoter for three different phage infections (wild-type, $2^{-}$, and $5^{-}$) are shown in Fig. 8. The lag time increased approximately linearly with the distance from the late promoter. The slope in Fig. 8 indicates that RNA polymerase transcribed the late operon at a rate of ca. 50 nucleotides per s. This value is in reasonable agreement with the 55 and 25 nucleotides per s previously determined for Escherichia coli RNA polymerase (4, 27). The linear increase in lag time with distance from the late promoter strongly reinforces the idea that there is only a single late promoter on the P22 chromosome.

The lag times were invariant with respect to the genotype of the infecting phage to within the limits of experimental error, indicating that no new promoters were activated in the late operon under any of these conditions. It is therefore unlikely that the autogenous modulation of the scaffolding protein gene, 8 , was mediated through the activation of a new scaffolding protein gene-specific promoter near gene 8 . If this were true, the $2^{-}$infection (which synthesizes three-

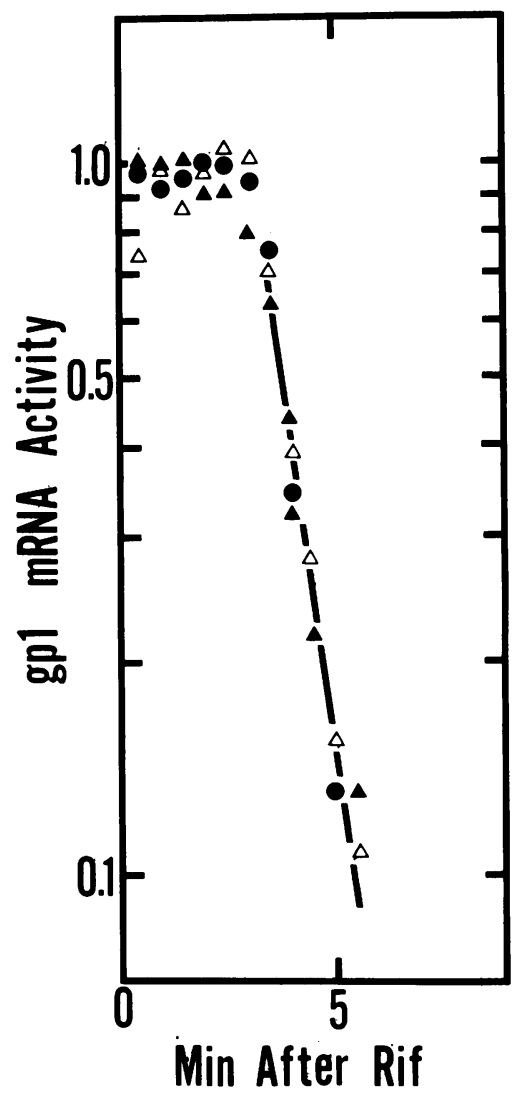

FIG. 2. Functional decay of the gene 1 transcript. Cells were infected with wild-type $(\triangle), 2^{-}(\circlearrowleft)$, or $5^{-}(\Delta)$ phage, and samples were prepared as in the legend to Fig. 1. The gpl protein bands in the gels were quantitated as described in the text. Each individual point is plotted at the midpoint of the labeling period. For ease of comparison, the ordinates for the different curves are normalized so that the exponential portions of the curves coincide. 


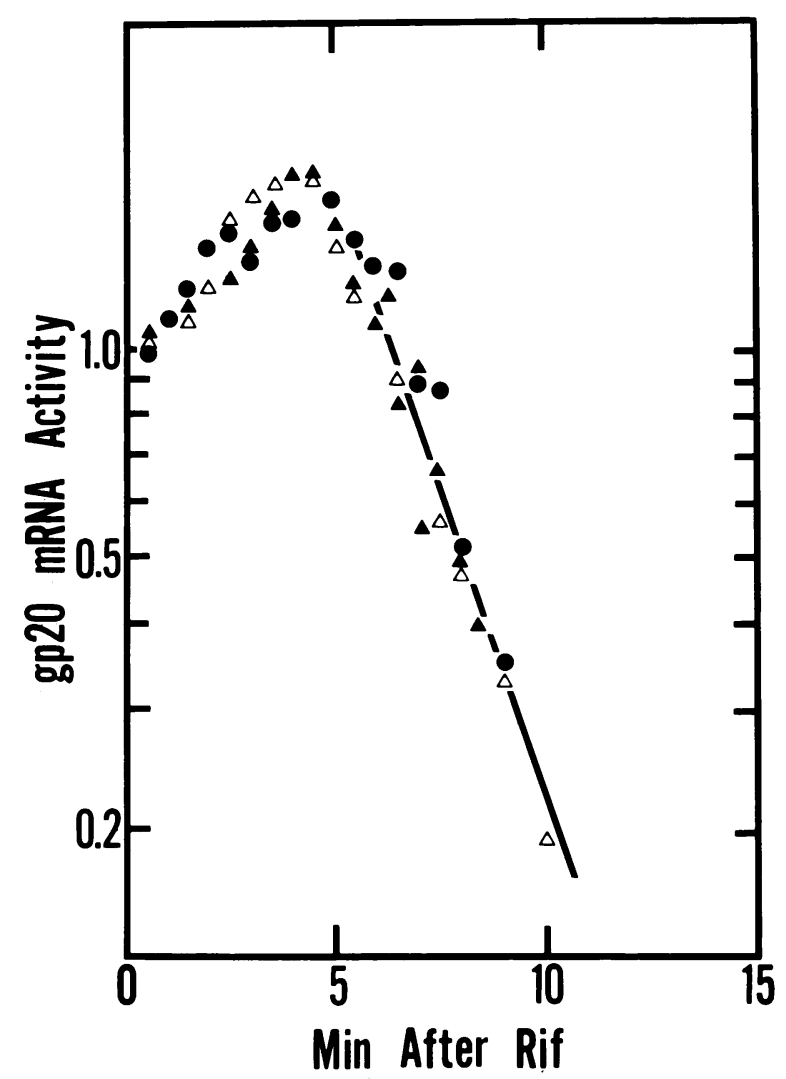

FIG. 3. Functional decay of the gene 20 transcript. The data were determined from the experiment described in the legend to Fig. 2. Symbols are defined in the legend to Fig. 2.

to sixfold as much scaffolding protein as wild-type or $5^{-}$ infections [15]) should have had a significantly shorter lag time.

The exponential decay portions of the different curves Fig. 2 through 7 were also quite similar. In only one case was the half-life significantly affected by mutation. The scaffolding protein transcript was about threefold less stable in $5^{-}$-infected cells than it was in $2^{-}$- or $3^{-}$-infected cells (Fig. 6). Wild-type P22-infected cells showed a half-life for the gene $8 \mathrm{mRNA}$ intermediate between that found in $5^{-}$- and $2^{-}$- or $3^{-}$-infected cells (data not shown). Half-lives determined from the exponential portions of the curves in Fig. 2 through 7 are given in Table 1 .

A curious feature of these results is that the functional half-life of the coat protein transcript increased with time after infection, whereas the functional half-lives of the other late gene transcripts remained constant. At $20 \mathrm{~min}$ after infection, the functional half-life of the gene 5 message was 1.5 to $2.0 \mathrm{~min}$, and this increased to 5 to $7 \mathrm{~min}$ by $60 \mathrm{~min}$ after infection (Fig. 9). This is reflected by a break in the slope of the exponential portion of the curve shown in Fig. 7. If the gene 5 mRNA increased in functional stability with time after infection, then the coat protein should have been made at higher rate, relative to the other late proteins, at late times after infection. To test this prediction, we performed a detailed time course of the rates of phage late protein synthesis (in a $2^{-}$infection) by pulse-labeling infected cells for 1 min with $\left[{ }^{35} S\right]$ methionine as described above (in the absence of rifampin) and quantitating the amounts of the various phage-specific proteins synthesized during the pulses in SDS-polyacrylamide gels. The rates of synthesis of several of the late proteins (gp1, gp8, and gp20) relative to gp5 are shown in Fig. 10. The rate of coat protein synthesis did in fact increase by a factor of 2 to 3 relative to the rate of synthesis of gp1 or gp20 between 35 and 65 min after infection. Since the level of gp8 is dependent upon the amount of gp 5 available $(5,15)$, its rate of synthesis is expected to parallel that of gp5.

\section{DISCUSSION}

Systemic regulation of expression of the $P 22$ late operon genes. The positive regulation of the late operon by gp23 is thought to occur by antitermination of a small leader transcript which is constitutively made from the late promoter $(16,26,34)$. After antitermination by gp 23 , RNA polymerase apparently makes a single, polycistronic transcript of the entire late operon. The data presented in Fig. 8 support this model and show that RNA polymerase transcribes the late operon at a rate of ca. 50 nucleotides per $\mathrm{s}$ at $30^{\circ} \mathrm{C}$.

If there is a single late promoter and terminator, then an equal number of transcripts must be made from each of the late operon genes. (In the related phage lambda late operon, this has been measured directly and found to be the case [23]). Yet, there is at least a 28 -fold variation in the level of expression of the different P22 late genes (Table 1). This systemic regulation of expression must be mediated at a posttranscriptional level. It is intriguing that the phage morphogenetic gene products are generally made in approximately the ratios found in the phage particles. Regulation of the relative concentrations of these proteins in infected cells

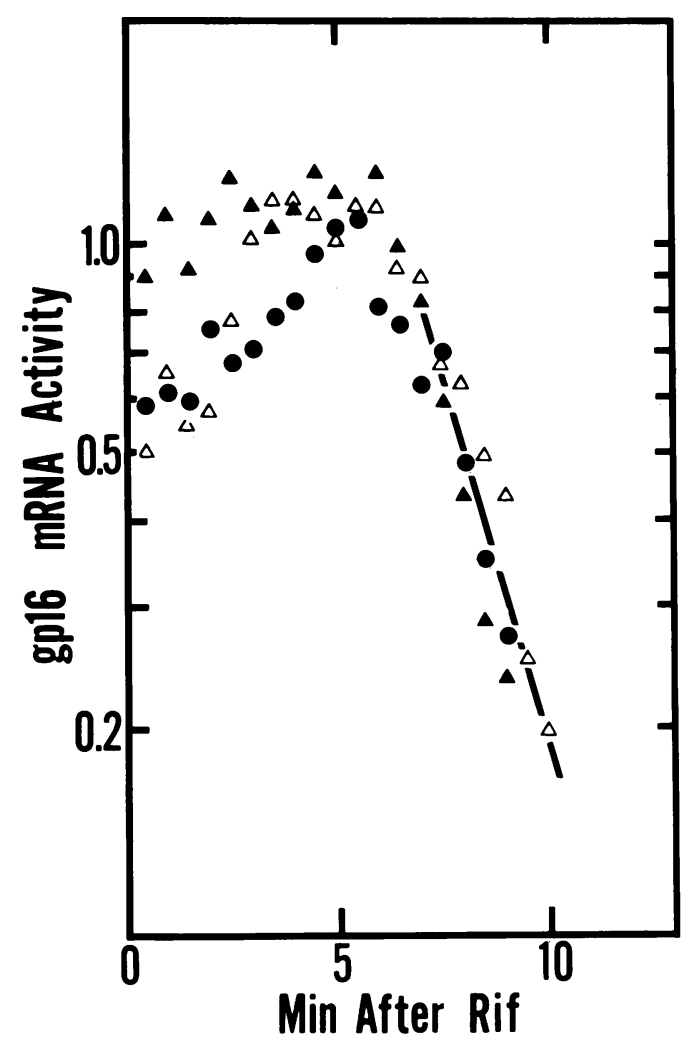

FIG. 4. Functional decay of the gene 16 transcript. The data were determined from the experiment described in the legend to Fig. 2. Symbols are defined in the legend to Fig. 2. 
is likely to be required for efficient phage assembly (7). The differences in the number of times a given transcript is translated cannot be explained completely by the rate at which it is degraded (Table 1 ). There is at least a 28 -fold range among the rates of late gene expression but only a 7 - to 8 -fold range in the mRNA decay rates. There is a general nonlinear trend for those proteins which are made in higher amounts to have more stable transcripts. Thus, this systemic regulation of late gene expression is apparently due in part to the relative stability of individual transcripts and in part to other factors. It seems likely that one of these other factors is the efficiency with which ribosomes load onto the individual transcripts or the rate at which the codons of the transcripts are translated $(24,25,30)$.

Although it has been found that phage mRNAs are in general more chemically stable than bulk mRNA in uninfected bacteria, they are in most cases as functionally unstable as host mRNAs $(9,24,25,35,38)$. Our results extend this to the P22 late operon. Measurements of the functional half-life of bulk enterobacterial $\mathrm{mRNA}$ range from 1.1 to $3.5 \mathrm{~min}(1,10,17)$, similar to the rates of inactivation of the P22 late operon transcripts. Since it takes an RNA polymerase 7 to $10 \mathrm{~min}$ to transcribe the late operon and the half-lives of at least four of the late gene transcripts are less than $2.6 \mathrm{~min}$, it is unlikely that an appreciable amount of full-length late operon message is ever present in the infected cell.

Because the decay of the individual P22 late gene transcripts is exponential, it is likely that functional inactivation is the result of a random event in time (33). Such an event

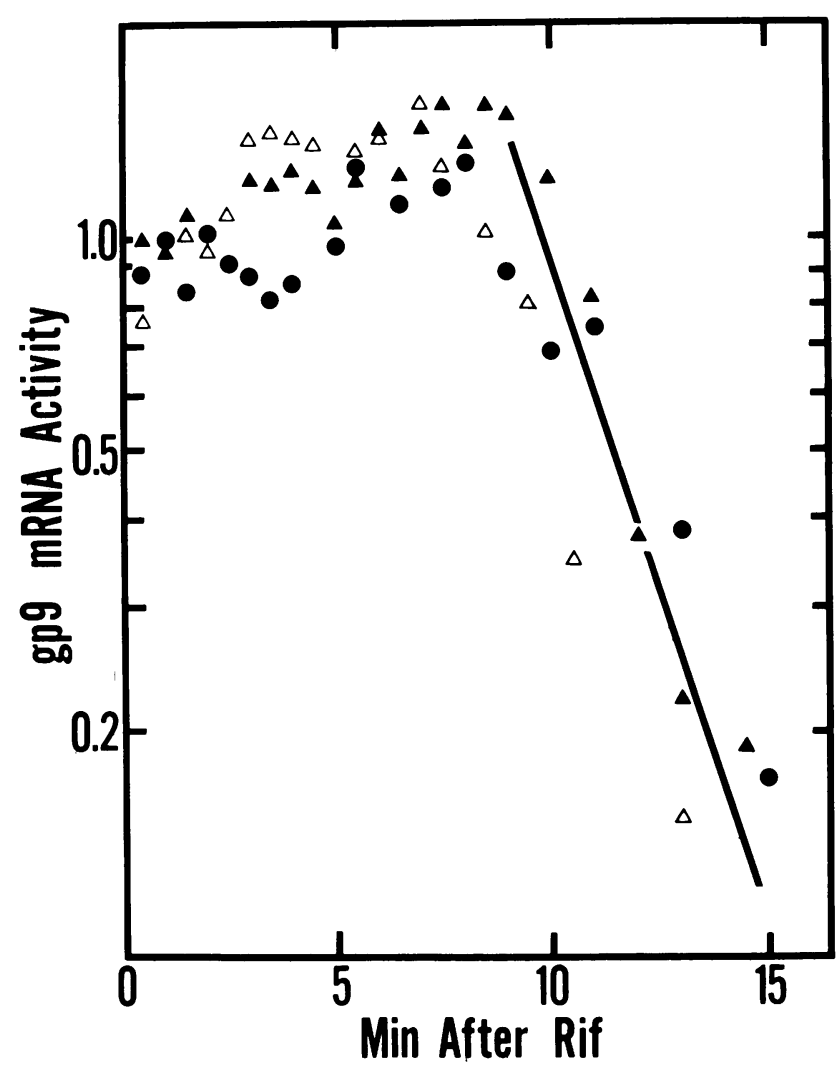

FIG. 5. Functional decay of the tail gene transcript. The data were determined from the experiment described in the legend to Fig. 2. Symbols are defined in the legend to Fig. 2.

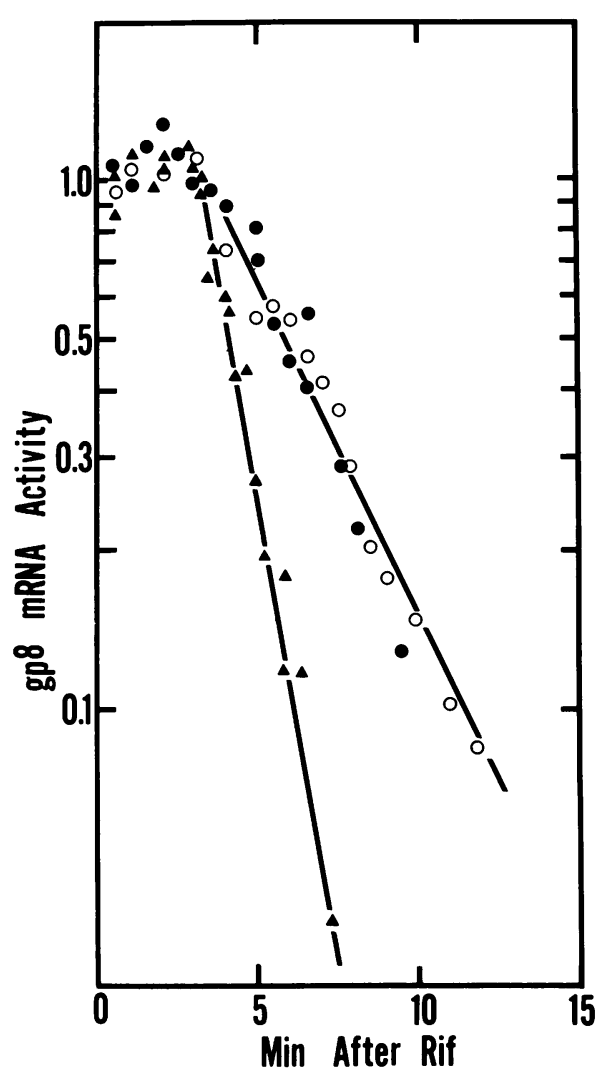

FIG. 6. Functional decay of the scaffolding protein gene transcript. The data were determined from the experiment described in the legend to Fig. 2, except that data from a $3^{-}$infection $(O)$ replace those of the wild-type infection. Other symbols are defined in the legend to Fig. 2.

has been proposed to be endonucleolytic attack for certain bacterial mRNAs $(2,13,14)$. It has also been proposed that decay results from exonucleolytic attack beginning at or near the $5^{\prime}(31)$ or the $3^{\prime}$ end (8) of an mRNA molecule. The fact that the functional transcript of a promoter-distal P22 late gene may decay more rapidly than that of a more proximal gene (e.g., genes 16 and $20 \mathrm{mRNAs}$ decay faster than those of genes 5 and 8 at late times in a $2^{-}$infection) indicates that some specific or preferred internal inactivating events may occur.

We also see a general trend for the largest gene transcripts to decay more rapidly than those of the smaller genes (Table 1). However, since the relationship is not linear (e.g., genes 5 and 20), inactivation events probably do not occur at random sites on the messengers. Similar conclusions have been drawn for the phage lambda late region by Ray and Pearson (24). Since it is thought that free ribosomes can load at many internal sites on procaryotic polycistronic messengers $(16,18)$, we favor a model in which the transcript of each gene is inactivated independently by events whose probability in time varies from gene to gene.

Posttranscriptional control of scaffolding protein gene expression. In previous studies we have shown that the P22 scaffolding protein itself modulates the rate at which additional scaffolding protein is made $(5,37)$. It was found to depress expression of the scaffolding protein gene only when not assembled into proheads. In the experiments presented here, we have found that the functional half-life of the 


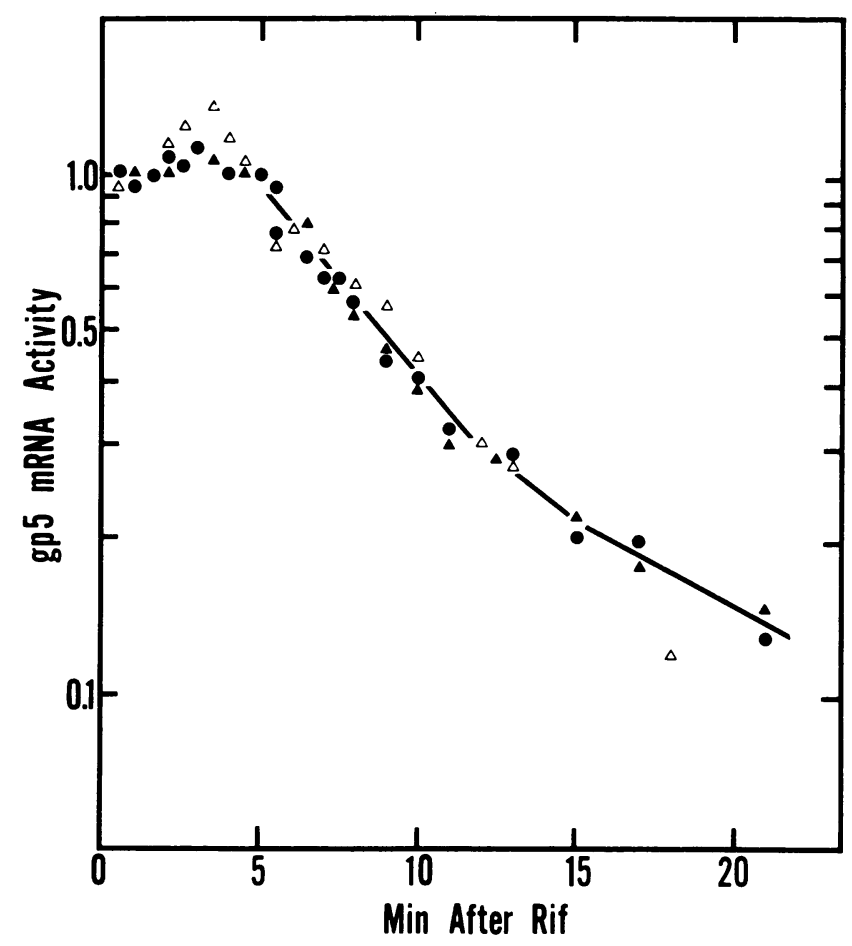

FIG. 7. Functional decay of the coat protein gene transcript. The data were determined from the experiment described in the legend to Fig. 2. $\Delta, 5^{-}\left(\mathrm{am}^{-}\right.$fragment); other symbols are defined in the legend to Fig. 2.

scaffolding protein gene transcript is about threefold greater in $2^{-}$- or $3^{-}$-infected cells than in $5^{-}$-infected cells. These data also show that the lag time before exponential decay for the gene $8 \mathrm{mRNA}$ is indistinguishable in the same three infections, indicating no activation of a new promoter near the scaffolding protein gene during either infection. We therefore conclude that the regulation must be posttranscriptional. Since the steady-state concentration of a message is proportional to the half-life of that message, it is possible to explain the three- to fivefold autogenous modulation of the scaffolding protein gene in terms of the observed rates of message inactivation.

Unassembled scaffolding protein may be directly responsible for the more rapid inactivation of the scaffolding protein mRNA by binding, cleaving, or modifying the transcript. However, a number of workers have pointed out that mRNAs can be stabilized if ribosomes are slowed down or stopped on a transcript $(32,35)$ or destabilized if ribosomes are absent $(11,19,28,35)$. Thus, at present, it is not possible to distinguish between mechanisms in which unassembled scaffolding protein directly inactivates the transcript and mechanisms in which it blocks translation at ribosome loading, for example.

Coat protein gene expression. It has previously been thought that the P22 coat protein gene was regulated in concert with the rest of the genes in the the phage late operon (except genes 8 and 9; references 5, 15); however, experiments presented here suggest that the half-life of the coat protein transcript increases with time after infection, whereas the half-lives of the other late genes tested, 1, 9, 16, and 20, do not. This change in apparent functional stability is reflected in the rate of synthesis of the coat protein gene relative to other late proteins. We do not yet understand what is

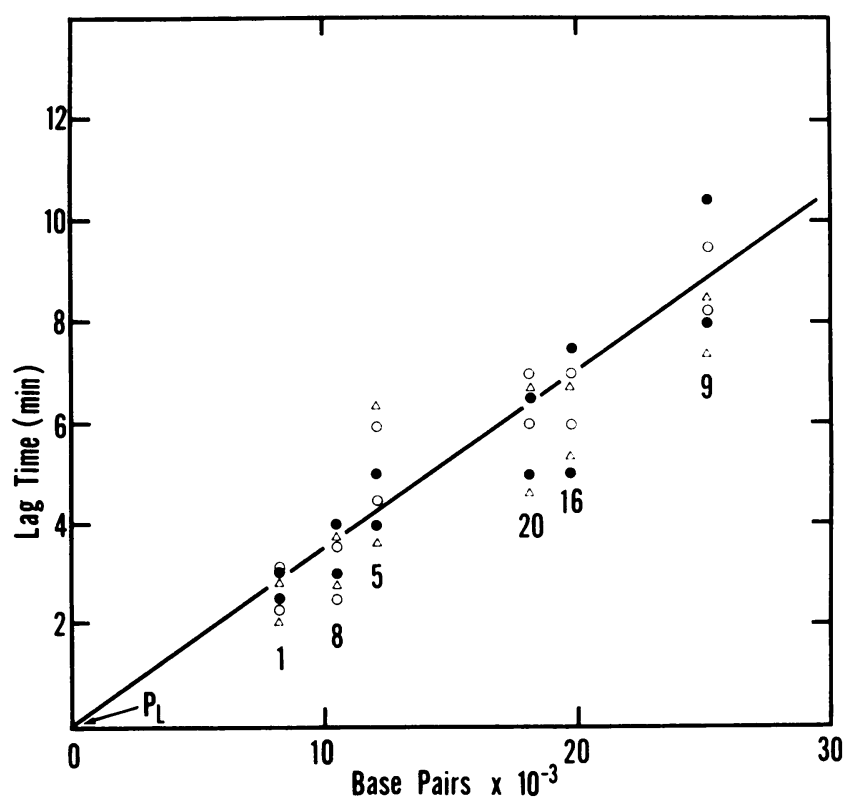

FIG. 8. The lag time for each gene is proportional to its distance from the late promoter. The functional decay curves for the transcripts of the six genes indicated were determined as described in the text. The indicated lag times were determined by inspection of the curves. The two points given for each genotype of infecting phage represent the outside limits of the variation in several experiments. The lag times were determined after P22 wild-type $(\triangle), 2^{-}(0)$, and $5^{-}(O)$ infection of nonpermissive cells. Each of the infecting phages also carried the $c 1-7$ and $13^{-}$am $\mathrm{H} 101$ alleles. The distance from the late promoter was estimated from the physical map of Rutila and Jackson (29).

responsible for this posttranscriptional regulation of the coat protein gene.

If gp1, gp7, gp16, or gp20 is not present in sufficient amounts when the assembly of the phage particles is begun, defective phagelike particles lacking these proteins are assembled that cannot be rescued by their subsequent addition $(3,22)$. Thus, an excess of these proteins early after initiation of late protein synthesis could ensure that they will not be bypassed in the normal phage assembly process; making coat protein at a slower initial rate might contribute toward this end.

TABLE 1. Functional half-lives of P22 late operon transcripts

\begin{tabular}{rcccc}
\hline Gene & $\begin{array}{c}\text { Relative rate } \\
\text { of } \\
\text { expression }\end{array}$ & $\begin{array}{c}\text { Gene length } \\
\text { (kilobase pairs) }\end{array}$ & \multicolumn{2}{c}{$\begin{array}{c}\text { Functional } \\
\text { mRNA half- } \\
\text { life (min) for } \\
\text { infection type: }\end{array}$} \\
\cline { 4 - 5 } & 1.0 & 2.6 & 0.7 & $2^{-}$ \\
\hline 8 & 15.2 & 1.1 & 2.7 & 0.7 \\
5 & 28.1 & 1.5 & 5.5 & 4.8 \\
20 & 7.2 & 1.4 & 1.7 & 1.4 \\
16 & 1.1 & 1.8 & 1.8 & 1.4 \\
9 & 1.7 & 2.1 & 1.6 & 1.2 \\
\hline
\end{tabular}

a Molar rates of synthesis are from the experiment described in the legend to Fig. 9 , a $2^{-}$infection at $55 \mathrm{~min}$ after infection. Rates are normalized to that of $\mathrm{gp} 1$.

${ }^{b}$ Calculated from the molecular weights of the proteins coded by the genes (3)

' Functional half-lives were measured from the data in Fig. 2 through 7. These values vary ca. $\pm 20 \%$ between experiments. 


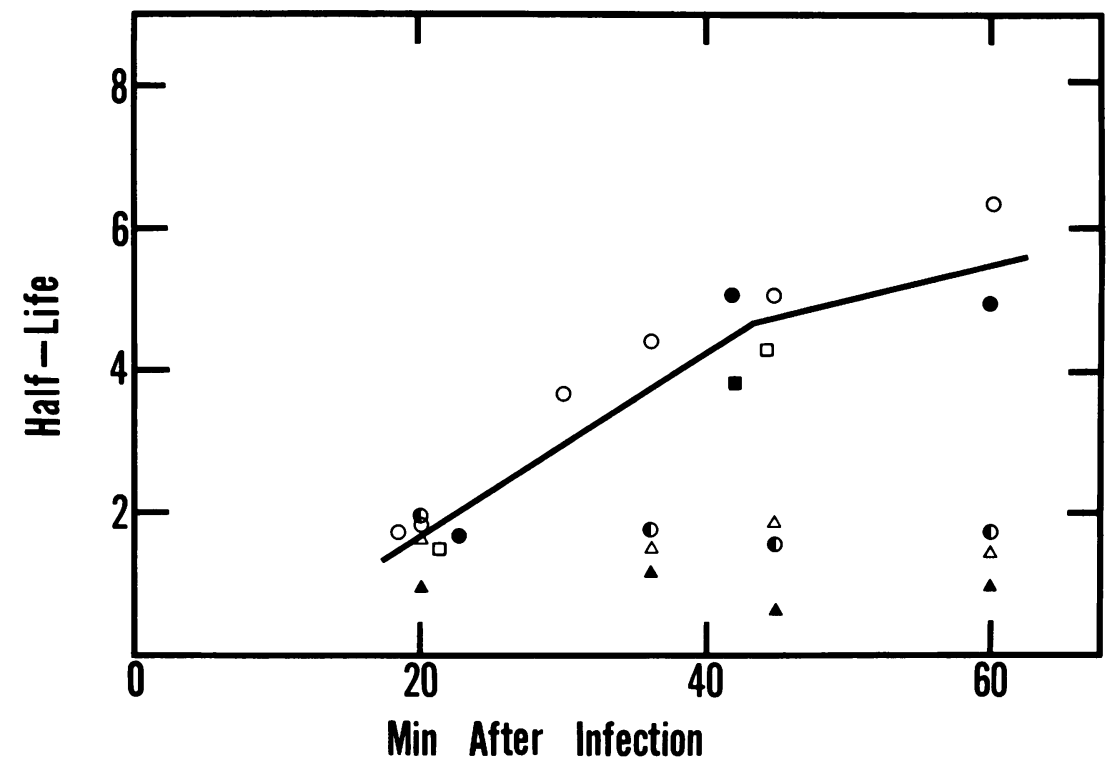

FIG. 9. Increased stability of the coat protein transcript with time after infection. The half-lives of the indicated transcripts were determined from the initial slope of the exponential portion of the decay curves in experiments similar to that described in the text and legend to Fig. 2, except that the time of rifampin addition (plotted on the abscissa) was varied. The half-life of the coat protein transcript was determined after infection by wild-type (O), $2^{-}(\Theta), 3^{-}(\square)$, and $5^{-}(\square)$ phages. Also shown are the half-lives of the gene $1(\Delta)$, gene $20(\triangle)$,

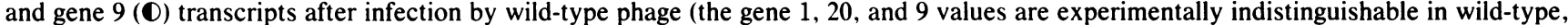
$2^{-}$, and $5^{-}$infections). Each of the phages also carried the $c 1-7$ and $13^{-}$am $\mathrm{H} 101$ alleles.

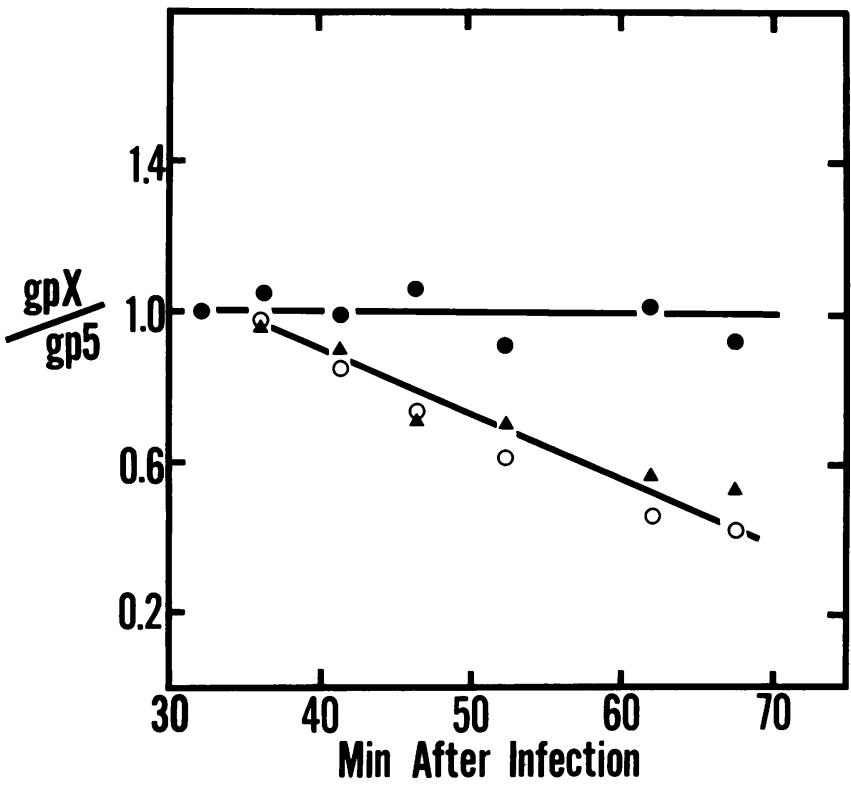

FIG. 10. Time course of coat protein synthesis relative to other late proteins. Cells were infected with P22 c1-7 $2^{-}$-am $\mathrm{H} 200$ $13^{-}$am $\mathrm{H} 101$, pulse-labeled for $1 \mathrm{~min}$ with $\left[{ }^{35} \mathrm{~S}\right]$ methionine at the times indicated, harvested, and subjected to SDS-polyacrylamide gel electrophoresis and autoradiography, and protein bands were quantitated as described in the text. gpX represents gp1 $(O)$, gp20 $(\Delta)$, or scaffolding protein $(\Theta)$. The ratios plotted on the ordinate were, for ease of comparison, normalized to their values at $32 \mathrm{~min}$ after infection.

\section{ACKNOWLEDGMENTS}

This work was supported by Public Health Service grant GM21975 from the National Institute of Health and National Science Foundation grant PCM8017177.
We thank Jonathan King, David Botstein, and Ethel Jackson for helpful discussions and access to unpublished results and A. Holmes for technical assistance.

\section{LITERATURE CITED}

1. Barnsley, P., and B. Sells. 1977. Functional inactivation rates of messenger RNA molecules coding for individual ribosomal proteins of Escherichia coli. Mol. Gen. Genet. 153:121-127.

2. Blundell, M., and D. Kennell. 1974. Evidence for endonucleolytic attack in decay of lac messenger RNA in Escherichia coli. J. Mol. Biol. 83:143-161.

3. Botstein, D., C. Waddell, and J. King. 1973. Mechanism of head assembly and DNA encapsulation in Salmonella phage P22. I. Genes, proteins, structures and DNA maturation. J. Mol. Biol. 80:669-695.

4. Bremer, H., and D. Yuan. 1968. RNA chain growth-rate in Escherichia coli. J. Mol. Biol. 38:163-180.

5. Casjens, S., M. Adams, C. Hall, and J. King. 1985. Assemblycontrolled autogenous modulation of the bacteriophage P22 scaffolding protein gene. J. Virol. 53:174-179.

6. Court, D., B. de Crombrugghe, S. Adya, and M. Gottesman. 1980. Bacteriophage lambda hin function. II. Enhanced stability of lambda messenger RNA. J. Mol. Biol. 138:731-743.

7. Georgopoulos, C., K. Tilly, and S. Casjens. 1983. Lambdoid phage head assembly, p. 279-304. In R. Hendrix, J. Roberts, F. Stahl, and R. Weisberg (ed.), Lambda II. Cold Spring Harbor Laboratory, Cold Spring Harbor, N.Y.

8. Guarneros, G., C. Montanez, T. Hernandez, and D. Court. 1982. Posttranscriptional control of bacteriophage lambda int gene expression from a site distal to the gene. Proc. Natl. Acad. Sci. U.S.A. 79:238-242.

9. Gupta, R., and D. Schlessinger. 1975. Differential modes of chemical decay for early and late lambda messenger RNA. J. Mol. Biol. 92:311-318.

10. Gupta, R., and D. Schlessinger. 1976. Coupling of rates of transcription, translation, and messenger ribonucleic acid degradation in streptomycin-dependent mutants of Escherichia coli. J. Bacteriol. 125:84-93.

11. Har-EI, R., A. Silberstein, J. Kuhn, and M. Tal. 1979. Synthesis and degradation of lac mRNA in E. coli depleted of $30 \mathrm{~S}$ 
ribosomal subunits. Mol. Gen. Genet. 173:135-144.

12. Hendrix, R. 1971. Identification of proteins coded in phage lambda, p. 355-370. In A. D. Hershey (ed.), The bacteriophage lambda. Cold Spring Harbor Laboratory, Cold Spring Harbor. N.Y.

13. Kano, Y., and F. Imamoto. 1979. Evidence for endonucleolytic cleavage at the 5'-proximal segment of the $\operatorname{trp}$ messenger RNA of Escherichia coli. Mol. Gen. Genet. 172:25-30.

14. Kim, L., and D. Kennell. 1979. Models for decay of Escherichia coli messenger RNA and evidence for inactivating cleavages between messages. J. Mol. Biol. 135:369-390.

15. King, J., C. Hall, and S. Casjens. 1978. Control of the synthesis of phage P22 scaffolding protein is coupled to capsid assembly. Cell 15:551-560.

16. Kozak, M. 1978. How do eucaryotic ribosomes select initiation regions in messenger RNA? Cell 15:1109-1123.

17. Kuwano, M., M. Ono, H. Endo, K. Hori, K. Nakamura, Y. Hirota, and Y. Ohnishi. 1977. Gene affecting longevity of messenger RNA: a mutant of Escherichia coli with altered mRNA stability. Mol. Gen. Genet. 154:279-285.

18. Lodish, H. 1976. Translational control of protein synthesis. Annu. Rev. Biochem. 45:39-72.

19. Morse, D., and P. Primakoff. 1970. Relief of polarity in E. coli by "suA". Nature (London) 226:38-31.

20. O'Farrell, P., L. Gold, and W. Huang. 1973. Identification of prereplicative bacteriophage T4 proteins. J. Biol. Chem. 248:5499-5501.

21. Ono, M., and M. Kuwano. 1979. A conditional lethal mutation in an Escherichia coli strain with a longer chemical lifetime of messenger RNA. J. Mol. Biol. 129:343-357.

22. Poteete, A., V. Jarvick, and D. Botstein. 1979. Encapsulation of phage P22 DNA in vitro. Virology 95:550-564.

23. Ray, P., and M. Pearson. 1974. Evidence for post-transcriptional control of the morphogenetic genes of bacteriophage lambda. J. Mol. Biol. 85:163-175.

24. Ray, P., and M. Pearson. 1975. Functional inactivation of bacteriophage lambda morphogenetic gene mRNA. Nature (London) 253:647-650.

25. Ray, P., and M. Pearson. 1976. Synthesis of morphogenetic proteins by mutants of bacteriophage lambda carrying tandem genetic duplications. Virology 73:381-388.

26. Roberts, J., C. Roberts, S. Hilliker, and D. Botstein. 1976. Transcription termination and regulation in bacteriophages P22 and lambda. p. 707-718. In R. Losick and M. Chamberlin (ed.), RNA polymerase. Cold Spring Harbor Laboratory, Cold Spring Harbor, N.Y.

27. Rose, J., R. Mosteller, and C. Yanofsky. 1970. Tryptophan messenger ribonucleic acid elongation rates and steady-state levels of tryptophan operon enzymes under various growth conditions. J. Mol. Biol. 51:540-550.

28. Russell, M., L. Gold, H. Morrisset, and P. O'Farrell. 1976. Translational. autogenous regulation of gene 32 expression during bacteriophge T4 infection. J. Biol. Chem. 251:7263-7270.

29. Rutila, J., and E. Jackson. 1981. Physical map of the bacteriophage P22 genome. Virology 113:769-775.

30. Sanger, F., A. Coulson, G. Hong, D. Hill, and G. Petersen. 1983. Nucleotide sequence of bacteriophage lambda DNA. J. Mol. Biol. 162:729-773.

31. Schlessinger, D., K. Jacobs, and R. Gupta. 1977. Decay of individual Escherichia coli trp messenger RNA molecules is sequentially ordered. J. Mol. Biol. 110:421-439.

32. Schneider, E., M. Blundell, and D. Kennell. 1978. Translation and mRNA decay. Mol. Gen. Genet. 160:121-129.

33. Schwartz, T., E. Craig, and D. Kennell. 1970. Inactivation and degradation of messenger ribonucleic acid from the lactose operon of Escherichia coli. J. Mol. Biol. 54:299-311.

34. Susskind, M. M., and D. Botstein. 1978. Molecular genetics of bacteriophage P22. Microbiol. Rev. 42:385-413.

35. Walker, A., M. Wash, D. Pennica, P. Cohen, and H. Ennis. 1976. Transcription-translation and translation-messenger DNA decay coupling: separate mechanisms for different messengers. Proc. Natl. Acad. Sci. U.S.A. 73:1126-1130.

36. Weinstock, G., P. Riggs, and D. Botstein. 1980. Genetics of bacteriophage P22. III. The late operon. Virology 106:82-91.

37. Wyckoff, E., and S. Casjens. 1985. Autoregulation of the bacteriophage P22 scaffolding protein gene. J. Virol. 53:192-197.

38. Yamada, Y., P. Whitaker, and D. Nakada. 1974. Functional instability of T7 early mRNA. Nature (London) 248:335-338. 